\title{
Physical Simulation of the Water-Conducting Fracture Zone of Weak Roofs in Shallow Seam Mining Based on a Self-Designed Hydromechanical Coupling Experiment System
}

\author{
Hao Zha $\mathbb{D}^{1}{ }^{1}$ Weiqun Liu $\mathbb{D},{ }^{1,2,3}$ and Qinghong Liu $^{2}$ \\ ${ }^{1}$ State Key Laboratory for Geomechanics \& Deep Underground Engineering, China University of Mining and Technology, Xuzhou, \\ Jiangsu 221116, China \\ ${ }^{2}$ School of Mechanics and Civil Engineering, China University of Mining and Technology, Xuzhou, Jiangsu 221116, China \\ ${ }^{3}$ College of Architecture and Civil Engineering, Wuyi University, Wuyishan 354300, China
}

Correspondence should be addressed to Weiqun Liu; wqliu@cumt.edu.cn

Received 25 June 2019; Revised 17 December 2019; Accepted 23 December 2019; Published 26 February 2020

Academic Editor: Paola Cianfarra

Copyright $\odot 2020$ Hao Zha et al. This is an open access article distributed under the Creative Commons Attribution License, which permits unrestricted use, distribution, and reproduction in any medium, provided the original work is properly cited.

Due to inappropriate mining practices, water-conducting fracture zones can develop in an aquifer, not only destroying the surfacewater environment but also causing water inrush, even hurting or killing workers. To avoid such disasters, investigating and simulating the evolution mechanism of water-conducting fractures are becoming a research focus in mining engineering, especially regarding the organisation and development of fractures. Our work mainly involved the design of low-strength analogous materials and the simulation of fracture evolution for weak-roof problems in shallow seam mining based on a selfbuilt experimental hydromechanical coupling system. The experimental results show that the vertical stress in the roof increases first as the working face approaches and finally decreases to near its initial value as the working face passes. The relationship between fracture depth and coal-seam excavation distance is obviously nonlinear. The leakage velocity of surface water remains stable in the early stage of excavation and increases when the fracture develops through the main aquifuge. The maximum fracture depth is $76.18 \mathrm{~m}$ for the Yili coal mine with weak roofs and shallow coal seams. In addition, we numerically simulated and verified the evolution patterns with the FLAC3D platform. The simulated fracture depth of the Yili coal mine agreed with the in situ borehole observation very well and was more accurate than the output of the empirical formula. Our work provides new methods and relevant data for research on the evolution of water-conducting fractures in weak roofs during shallow seam mining.

\section{Introduction}

The development of water-conducting fracture zones in overlying strata is a common mining problem. Once a water-conducting fracture zone develops in an aquifer, groundwater quickly begins to leak, causing problems in the surface environment and serious economic loss [1]. Therefore, water movement analysis is essential to research on the mechanism behind water-conducting fracture zone development in overburden strata during mining. Many scholars have predicted the development of water- conducting fracture zones in coal mining [2-10]. Zhang [11] introduced a mechanism for water-conducting zone development and proposed improved measures in coal mining based on hydrogeological conditions. A numerical simulation was carried out and compared with a field test to evaluate the risk of water inrush through the roof in Wuyang coal mine [12]. The impact factors for the development of a water-conducting fracture zone in a water-rich roof produced by long-span mining were analysed by Bai and $\mathrm{Tu}$ [13]. Majdi et al. [14] predicted the evolution mechanism of the height of the distressed zone of a roof in long-wall mining 


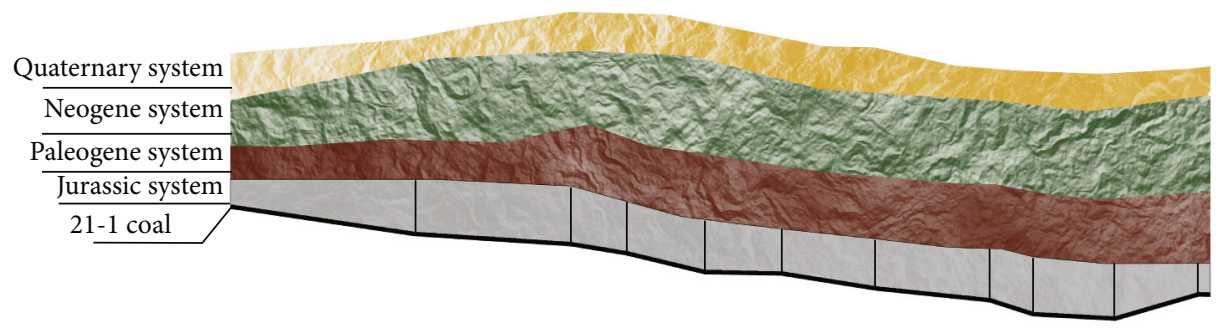

FIgURE 1: The distribution from the coal seam to Quaternary strata (selected).

and proposed a simple method to estimate the relationship between the caving zone of the roof and the thickness of the coal seam. The overburden model can be regarded as a beam (2D) or a slab (3D), and some scholars have applied a numerical simulation method to analyse the bending problem of this model $[15,16]$. Kong et al. [17] discussed the impact factors for the stress intensity and bearing capacity of roofs in long-wall mining based on theoretical analysis, numerical simulation and field tests. Wang et al. [18] studied the dynamic response mechanism of a mining roof with PFC2D.

A similarity model test is an effective method for researching the spatial relationship between geological and engineering structures [19]. Laboratory physical simulation of large-scale engineering problems based on similarity model tests is widely used in coal mining [20-22]. Chen et al. [23] developed similar low-intensity materials and applied them as mining backfill. Guo et al. [24] simulated water inrush from a mining floor and proposed preventive measures for coal mining.

International scholars have performed many studies on the stress and deformation of mining roofs. However, there are few studies on shallow seams with weak roofs and fragile surface environments, such as that in Xinjiang and other locations in Northwest China. When water inrush occurs in mining, surface water can be depleted, and a fragile ecological environment is vulnerable to damage [25]. Therefore, the study of fracture evolution and water inrush from weak roofs in shallow seam mining has great significance for resource development and ecologically sustainable construction.

Based on the geological conditions of shallow seams in the Yili coal mine, Xinjiang, a series of analogous materials with low strength and low permeability are developed. On this basis, the response of overburden strata and the evolution of water-conducting fractures in mining are simulated by a self-designed experimental hydromechanical coupling system. Moreover, the evolution mechanism of waterconducting fractures in weak roofs during shallow seam mining is analysed.

\section{Conditions of Mine Wells and Work Faces}

The mining field is located in the southeastern part of Huocheng County, Yili Kazakh Autonomous Prefecture, Xinjiang Uygur Autonomous Region. The mining field spans
$18.74 \mathrm{~km}$ in the $\mathrm{E}-\mathrm{W}$ direction and $9.32 \mathrm{~km}$ in the N-S direction, with an area of $113.3 \mathrm{~km}^{2}$. The project unit is the Yili New Coal Mine Co., Ltd., with a construction scale of 6 million tons per year. The 21103 working face is the first mining face, the floor elevation ranges from $+686 \mathrm{~m}$ to $+886 \mathrm{~m}$, the ground elevation ranges from $+853 \mathrm{~m}$ to $+950 \mathrm{~m}$, and the fully mechanised caving face is located in the south-eastern part of the area at $+660 \mathrm{~m}$. The design working length is $1150 \mathrm{~m}$, the inclination length is $120 \mathrm{~m}$, and the coal thickness is $3.8-4.2 \mathrm{~m}$. The main seam of the 21103 working face is 21-1 coal with an average depth of $120 \mathrm{~m}$. The dip in the stratum is between $4^{\circ}$ and $8^{\circ}$, and the average dip is $6^{\circ}$. A comprehensive mechanised coal mining method with longwall retreat and a double-cylinder shearer is adopted to cut coal, and the full-up fall caving method is used to manage the roof. The distribution from the coal seam to Quaternary strata (selected) is shown in Figure 1.

A comprehensive borehole histogram is shown in Figure 2. An aquifer with weak pores and a medium water content in the Quaternary layer is the indirect source of water filling the working face through the fracture zone. The Paleogene aquifer with a water-rich characteristic is the direct source of water filling of the working face through the caving zone. The fault structure is not developed in the original overburden strata, the groundwater recharge is poor, and the hydrogeological boundary is simple.

Taken together, the geological structure of the mining area, borehole histogram, and in situ protolith test (Table 1) indicate a shallow coal seam with weak-thin overburden strata. Although the structure of the stratum in the mining area is relatively complete, a fracture zone can easily develop in the overlying strata due to improper mining methods. The surface water and shallow groundwater can flow through the fracture zone of overburden strata to the working face in mining, leading to disastrous water inrush and serious damage to the fragile surface environment due to poor groundwater recharge conditions.

\section{Model Establishment and Experimental Testing of Water-Conducting Fracture Zone Evolution}

3.1. Similarity Principle of the Mechanical Model. The similarity principle of the model test states that the physical phenomena depicted in the model agree with the engineering prototype; that is, the model material, shape, and 


\begin{tabular}{|c|c|c|c|c|}
\hline Chronostratigraphic unit & $\begin{array}{c}\text { Drilling } \\
\text { histogram }\end{array}$ & Thickness (m) & Lithology & Remarks \\
\hline \multirow{3}{*}{ Quaternary system } & & 18 & Silt & Loess aquifuge \\
\hline & & 12 & Gravel & \multirow{2}{*}{ Phreatic aquifer } \\
\hline & & 24 & Mudstone & \\
\hline \multirow{5}{*}{ Neogene system } & & 18 & $\begin{array}{c}\text { Coarse } \\
\text { sandstone }\end{array}$ & \\
\hline & & 6 & $\begin{array}{c}\text { Muddy } \\
\text { siltstone }\end{array}$ & \multirow{4}{*}{ Main aquifuge } \\
\hline & & 4.6 & Mudstone & \\
\hline & & 8 & $\begin{array}{c}\text { Middle } \\
\text { sandstone }\end{array}$ & \\
\hline & & 8 & Fine sandstone & \\
\hline \multirow{3}{*}{ Paleogene system } & & 11 & Mudstone & \\
\hline & & 8 & Fine sandstone & \\
\hline & & 6.4 & Mudstone & \\
\hline \multirow{3}{*}{ Jurassic system } & & 12 & Siltstone & \\
\hline & & 8 & $\begin{array}{l}\text { Carbonaceous } \\
\text { mudstone }\end{array}$ & \\
\hline & & 4 & 21-1 Coal & \\
\hline Triassic system & --- & 10 & Mudstone & \\
\hline
\end{tabular}

Figure 2: Borehole histogram.

TABle 1: Main physical and mechanical properties of rock strata.

\begin{tabular}{lccccc}
\hline Layer number & Lithology & Density $\left(\mathrm{kg} / \mathrm{m}^{3}\right)$ & Compressive strength $(\mathrm{MPa})$ & Poisson's ratio & Modulus of elasticity $(\mathrm{GPa})$ \\
\hline 1 & Silt & 1700 & 0.7 & 0.31 & 1.6 \\
2 & Gravel & 2450 & 12.0 & 0.24 & 22.0 \\
3 & Mudstone & 2300 & 9.5 & 0.30 & 7.6 \\
4 & Coarse sandstone & 2410 & 23.2 & 0.27 & 17.8 \\
5 & Muddy siltstone & 2350 & 19.6 & 0.26 & 14.8 \\
6 & Mudstone & 2300 & 9.5 & 0.30 & 7.6 \\
7 & Middle sandstone & 2450 & 26.0 & 0.25 & 22.4 \\
8 & Fine sandstone & 2550 & 27.5 & 0.26 & 23.2 \\
9 & Mudstone & 2300 & 9.5 & 0.30 & 7.6 \\
10 & Fine sandstone & 2550 & 27.5 & 0.26 & 23.2 \\
11 & Mudstone & 2300 & 9.5 & 0.30 & 7.6 \\
12 & Siltstone & 2500 & 25.5 & 0.26 & 22.0 \\
13 & Carbonaceous mudstone & 2250 & 8.4 & 0.29 & 6.8 \\
14 & 21-1 coal & 1400 & 6.8 & 0.28 & 3.2 \\
\hline
\end{tabular}

load must follow certain rules [26, 27]. The ratio of a physical quantity with the same dimensions in the prototype and the model is called the similarity scale, which is expressed as $C$. $L$ is defined as length, $\gamma$ is severe, $\delta$ is dis- placement, $E$ is elastic modulus, $\sigma$ is stress, $\varepsilon$ is strain, $\sigma^{\mathrm{t}}$ is tensile strength, $\sigma^{\mathrm{c}}$ is compressive strength, $c$ is cohesion, $\varphi$ is friction angle, $\mu$ is Poisson's ratio, and $f$ is friction coefficient. 


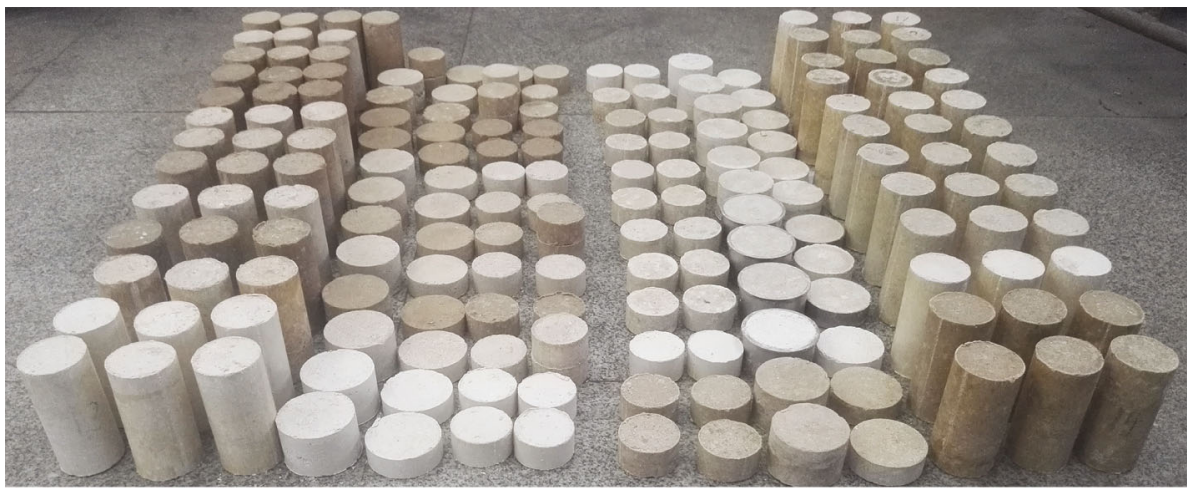

(a)

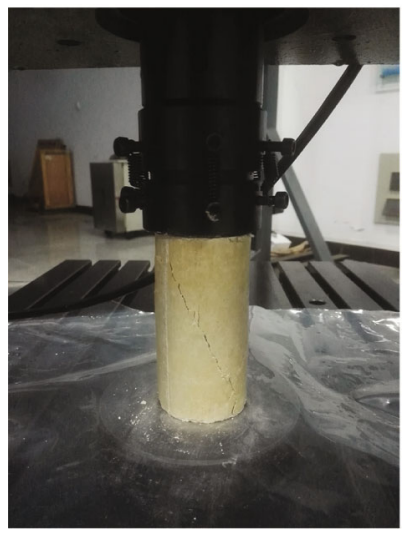

(b)

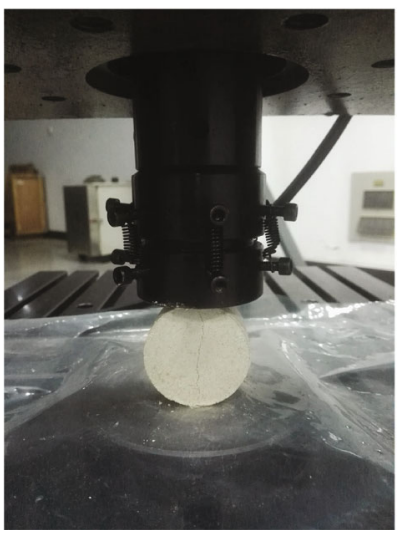

(c)

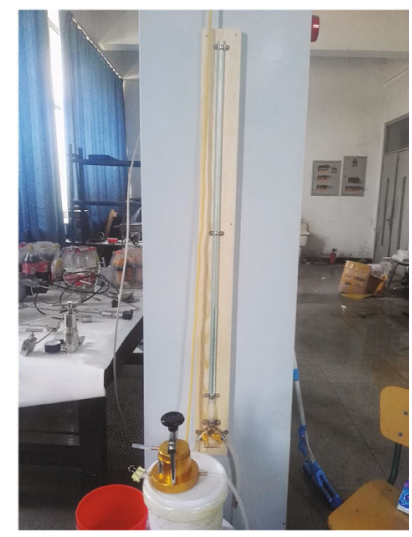

(d)

Figure 3: Similarity specimens and tests. (a) Similarity specimens. (b) Uniaxial compression test. (c) Brazilian splitting test. (d) Permeability test.

(1) All dimensions of 1 are equal to 1 , and the same scale is equal to the scale of the same dimension.

$$
\begin{aligned}
& C_{\varepsilon}=C_{\varphi}=C_{\mu}=1, \\
& C_{\sigma}=C_{\sigma^{\mathrm{c}}}=C_{\sigma^{\mathrm{t}}}=C_{E}=\mathrm{C}_{c}
\end{aligned}
$$

(2) According to the equation for the constitutive equation, the relationship between the displacement similarity scale, the geometric similarity scale, and the strain similarity scale is satisfied.

$$
C_{\delta}=C_{L} C_{\varepsilon}
$$

(3) According to the dimensional analysis, the relationships among the stress similarity ratio $C_{\sigma}$, bulk density similarity ratio $C_{\gamma}$, strain similarity ratio $C_{\varepsilon}$, and geometric similarity ratio $C_{L}$ are as follows:

$$
\begin{aligned}
& C_{\sigma}=C_{L} C_{\gamma}, \\
& C_{\sigma}=C_{\varepsilon} C_{E}
\end{aligned}
$$

3.2. Similarity Test Materials and Method. Regarding the geological conditions of the Yili coal mine, the gravel layer and surface silt layer are aquifers with numerous fractures, large porosity. and low strength and contain surface water and shallow groundwater. The third layer (mudstone) serves as a water barrier, while the fourth layer (coarse sandstone) and the fifth layer (muddy siltstone) act as supports for the overlying strata. On the basis of these condition and research on similar materials in fluid-solid coupling [28], similar materials with low strength and low permeability are designed. The main components of the aggregate are sifted fine sand (120 mesh) and barite. The binder is gypsum powder and Vaseline. The permeability is determined by the silicone oil content. To explore the impact of each component on the strength and permeability of materials, an orthogonal experiment with 5 factors and 5 levels was adopted (Table S-1). On the basis of the designed proportions, original materials are fabricated into cylindrical standard specimens with dimensions of $\Phi 50 \mathrm{~mm} \times 100 \mathrm{~mm}$, standard Brazilian disc specimens with dimensions of $\Phi 50 \mathrm{~mm} \times 25 \mathrm{~mm}$, and specimens with dimensions of $\Phi 80 \mathrm{~mm} \times 70 \mathrm{~mm}$ for the permeability test. There are 25 groups in total and 3 specimens in each group. Specimens are tested for uniaxial compression, Brazilian splitting, and permeability, respectively (Figure 3 ). The experimental results show that the compressive strength ranges from approximately $2.2 \mathrm{kPa}$ to $105 \mathrm{kPa}$, the tensile strength from $5.4 \mathrm{kPa}$ to $20.1 \mathrm{kPa}$, and the permeability from $0.08 \times 10^{-7} \mathrm{~m} / \mathrm{s}$ to $7.82 \times 10^{-7} \mathrm{~m} / \mathrm{s}$ (Table S-2). According to previous studies [29], the designed analogous materials meet the requirements of low strength 
and low permeability. Consequently, the proportions for similar geological models can be determined from the information in Table 2.

3.3. The Model Test System. To effectively explore the mechanism of the development of a water-conducting fracture zone in overlying strata during shallow seam mining, we designed a two-dimensional experimental "hydromechanical" coupling system (Figure 4). This system can simulate the evolution of water-conducting fractures with surface water and shallow groundwater in mining. Compared with the traditional similarity model experiment, this system can simulate more realistic conditions. According to the borehole histogram (Figure 2), the original rock test data (Table 1), and the similarity theory, we set the geometric similarity ratio at $1: 200$ and the density similarity ratio at $1: 1.5$. In addition, the time similarity ratio is $1: 20$, and the stress similarity ratio is $1: 300$.

The similarity model experimental device includes a test fixture, water-loading system, and measurement system. The length of the similarity model is $150 \mathrm{~cm}$, the height is $64 \mathrm{~cm}$, and the width is $20 \mathrm{~cm}$. A geoconstruction similarity model is made layer by layer through material mixing, mould loading, compaction, air drying, etc. To reduce the influence of interlayer forces on structural stability, mica sheets are laid between layers. Ten stress sensors and three displacement lines (Figure 5) are arranged to monitor the dynamic response of the stress in the overlying strata during mining. The stress measurement points are labelled No. 1 to No. 10 and are evenly distributed in the pillars in two rows, one $15 \mathrm{~cm}$ and one $30 \mathrm{~cm}$ above the coal seam. The main stress measurement systems are stress sensors and TST3826E static strain gauges. The three measurement lines are established at $7 \mathrm{~cm}, 27 \mathrm{~cm}$, and $47 \mathrm{~cm}$ above the coal seam, denoted line A, line $\mathrm{B}$, and line $\mathrm{C}$, respectively. Displacement is mainly monitored by the displacement measurement line. Finally, to retain water without changing the permeability, a hydraulic-loading device is embedded into the top silt, and the edge is sealed with water-proof glue (Figure 6). Because the rate of excavation of the original working face is $10 \mathrm{~m}$ per day (24 hours), the rate of excavation of the model working face, which can be calculated by the time similarity ratio, is $5 \mathrm{~cm}$ per 1.2 hours. Therefore, we excavate $10 \mathrm{~cm}$ per 2.4 hours to ensure that the overburden deformation is complete. Moreover, $15 \mathrm{~cm}$ protective coal pillars are set on both sides of the model to eliminate the impact of boundary perturbation. Therefore, the effective excavation distance of the model is $120 \mathrm{~cm}$.

3.4. Testing Results and Data Analysis. In the early stage of mining (Figure $7(\mathrm{a})$ ), the rock pressure increases steadily. When the excavated length reaches $20 \mathrm{~cm}(40 \mathrm{~m})$, the maximum displacement of line $C$ is $0.05 \mathrm{~cm}(0.1 \mathrm{~m})$, which is larger than those of lines $\mathrm{A}$ and $\mathrm{B}$. The overburden structure is relatively stable. A weak separation layer appears in the direct roof. The development of the fracture zone is slow, and the height of the fracture zone is $0.5 \mathrm{~cm}(1 \mathrm{~m})$. Meanwhile, the water level is stable (Figure 8).
At an excavation depth of $30 \mathrm{~cm}(60 \mathrm{~m})$, the rock pressure continues to increase steadily. Fracture development gradually accelerates. The fracture zone has not yet developed to the aquifer. The water level does not decrease significantly. When mining proceeds to $50 \mathrm{~cm}(100 \mathrm{~m}$ ) (Figure $7(\mathrm{~b})$ ), rock pressure monitoring shows that the stress at the No. 2 stress sensor decreases from the maximum value of $2.26 \mathrm{MPa}$ to $1.15 \mathrm{MPa}$, as well as No. 6 stress sensor (Figures 8(a) and $8(\mathrm{~b}))$. At the position of the open-off cut, the stress reaches the maximum value of $5.76 \mathrm{MPa}$ before it decreases, as detected by the No. 9 stress sensor (Figure 8(c)). The displacement monitoring line shows that the maximum bending subsidence of line $\mathrm{C}$ is $0.82 \mathrm{~cm}(1.64 \mathrm{~m})$. The height of the fracture zone has developed to $21.5 \mathrm{~cm}$ $(43 \mathrm{~m})$, and the fracture zone has reached the main aquifer and developed cross-layer fractures. Therefore, the water level drops rapidly beyond an excavation depth of $50 \mathrm{~cm}$ $(100 \mathrm{~m})$. With the development of the fracture zone, the growth rate of the fracture zone slows. In addition, a bent subsidence zone develops $46 \mathrm{~m}$ away from the coal seam. Due to the bent subsidence of the underlying strata, the overlying strata also possess a bearing capacity. Therefore, an obvious separation space occurs.

After excavation to $60 \mathrm{~cm}(120 \mathrm{~m})$, stresses at the No. 1, No. 2, No. 5, and No. 6 stress sensors decrease and stabilise gradually under the influence of the tension-shear fracture of strata. The stress increases slowly (Figures 8(a) and 8(b)) at No. 3, No. 4, No. 7, and No. 8 due to the excavation of the working face. At a height of the fracture zone of $31 \mathrm{~cm}$ $(62 \mathrm{~m})$, the fracture began to penetrate the main aquifer, resulting in a large deformation of the overlying strata, a further increase in the shallow water loss rate, a sharp decline in the water level, and a risk of water inrush. When the excavation distance of the working face reaches $70 \mathrm{~cm}(140 \mathrm{~m})$ (Figure $7(\mathrm{c})$ ), the displacement monitoring line shows that the strata at three locations along the measurement line have different degrees of fracture and bending. The maximum subsidence height from line A to line C is $1.34 \mathrm{~cm}(2.68 \mathrm{~m})$, $1.53 \mathrm{~cm}(3.06 \mathrm{~m})$, and $1.95 \mathrm{~cm}(3.9 \mathrm{~m})$, respectively. Numerous fractures develop and extend upward. To facilitate observation, grey image processing of the upper part of the goaf (Area A) is carried out (Figure $7(\mathrm{~d})$ ). The maximum height of the fracture zone develops to $34.65 \mathrm{~cm}(69.3 \mathrm{~m})$, and the number of large cracks in the penetrating layer increases, which leads to the stratified conduction of the fracture zone. Meanwhile, a bent subsidence zone has developed and reached the aquifuge. A subsidence separation space is formed between the aquifer and the aquifuge. A large amount of surface water leaks into the separation space. Numerous tensile cracks occur in the aquifuge due to the large deformation. Thus, the aquifuge has lost its water-proofing ability, which results in the acceleration of seepage and a large amount of surface water loss.

\section{Simulation of the Mechanism}

According to the experimental results, the development of fracture zones is the most intuitive reason for water inrush. The crack propagates through the main aquifer, causing 


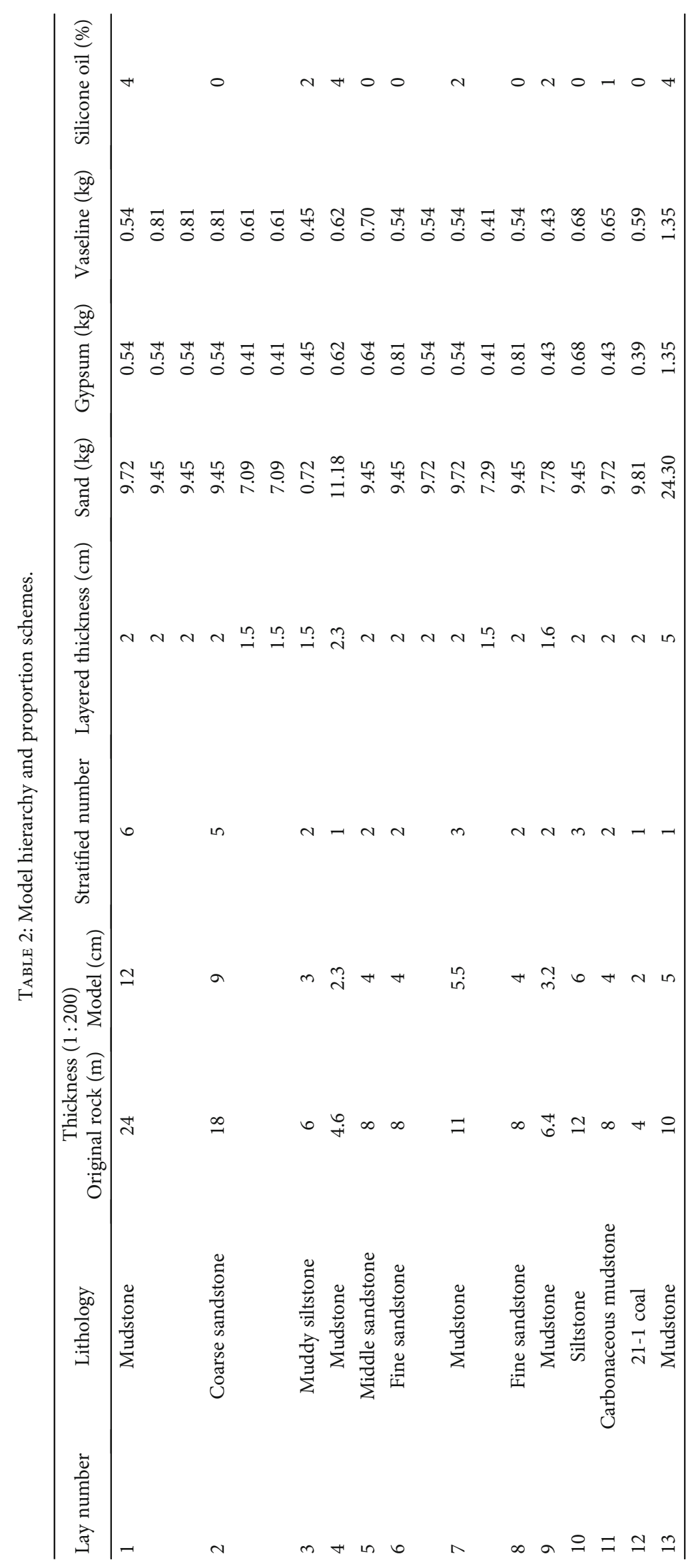




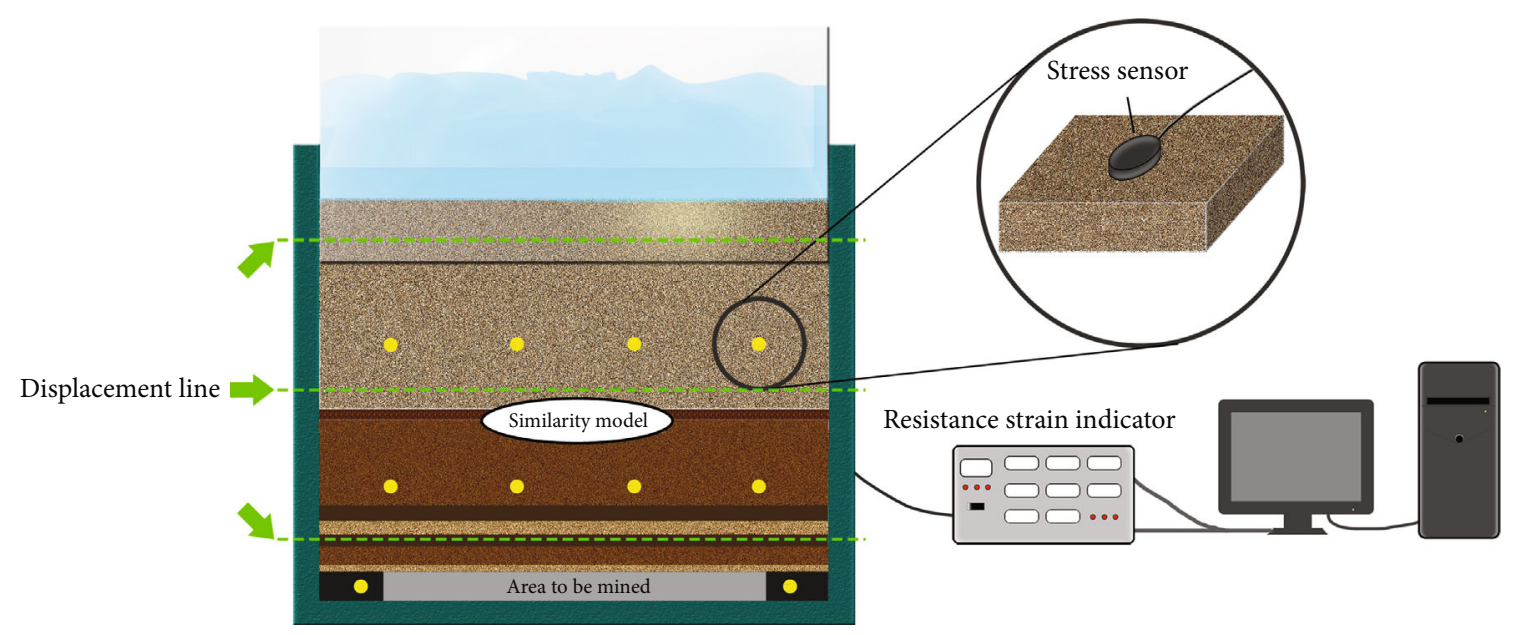

FIgURE 4: Two-dimensional "hydromechanical" coupling test system for surface water experiments.

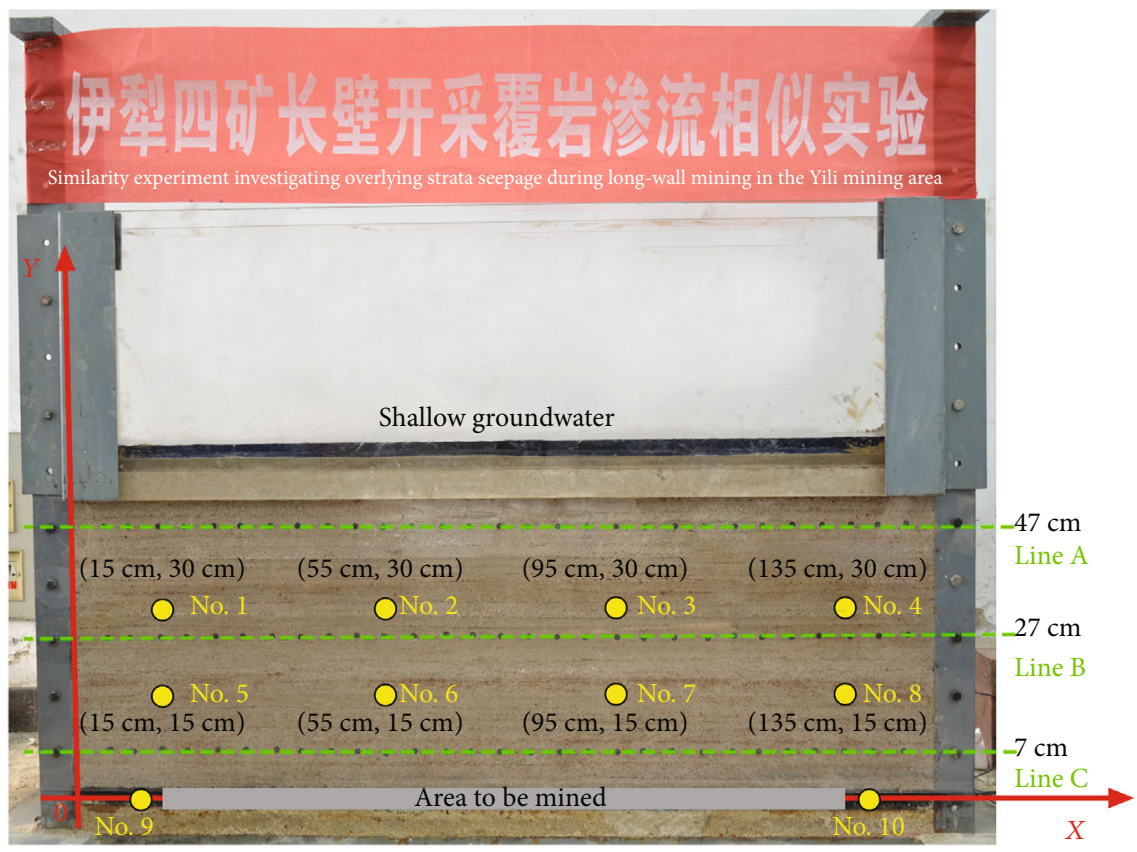

Legend

-- Displacement monitoring line

Stress sensor embedding point

FIGURE 5: Distribution of stress and displacement monitoring points.

instability in the main aquifer, the loss of bearing capacity of the aquifer, and the gradual leakage of water into the goaf. The main mechanism is shown in Figure 9. The formation of a goaf causes the roof to lose support from the bottom. Under the influence of gravity and pressure from the overlying strata, the roof undergoes subsidence and bending deformation and the internal stress increases gradually. Stress concentration (Figure 9(a)) occurs at both ends and the middle of the roof above the goaf during mining. With the increase in stress concentration, tension and shear cracks occur because the stress in strata reaches the ultimate yield stress. In addition, the deformation of and stress concentra- tion in strata continue to increase. The cracks gradually propagate through the strata, resulting in the formation of fracture groups (Figure 9(b)). Then, a separation space is formed in the upper part of the curved strata, which causes the overlying strata results to exhibit the same mechanical behaviour (Figure 9(c)). Finally, a fractured zone gradually develops upward through the aquifuge to the aquifer, and then water inrush occurs. With excavation, caving gangue accumulates gradually and supports the overlying strata, resulting in decreased deformation of the overlying strata, and the stress in the strata cannot reach the ultimate yield stress. As a result, the existing cracks stop propagating, and 


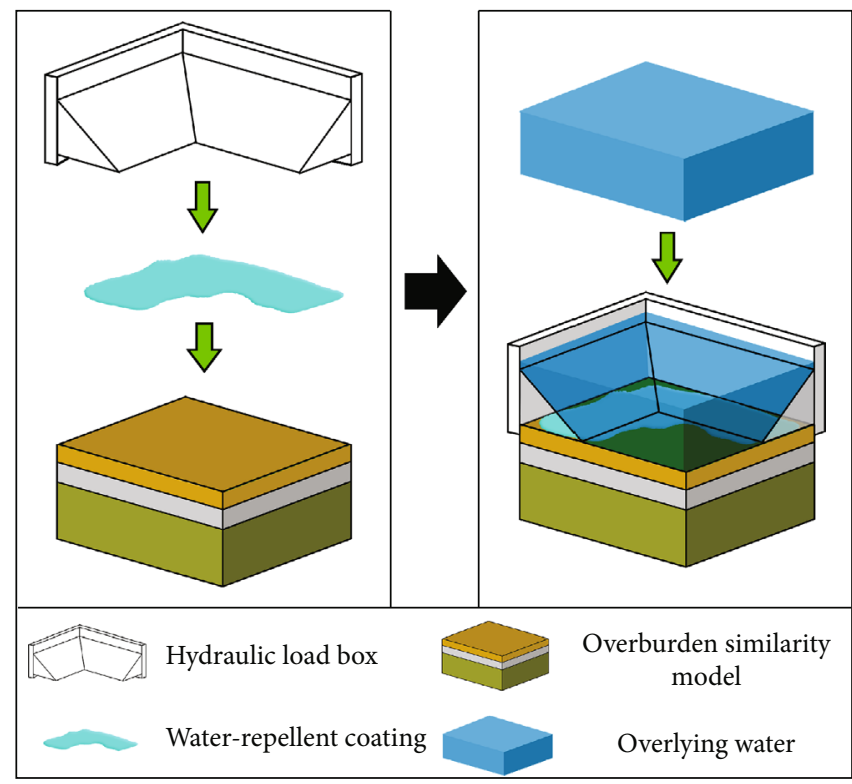

FigURE 6: Leakproof treatment of model boundaries.

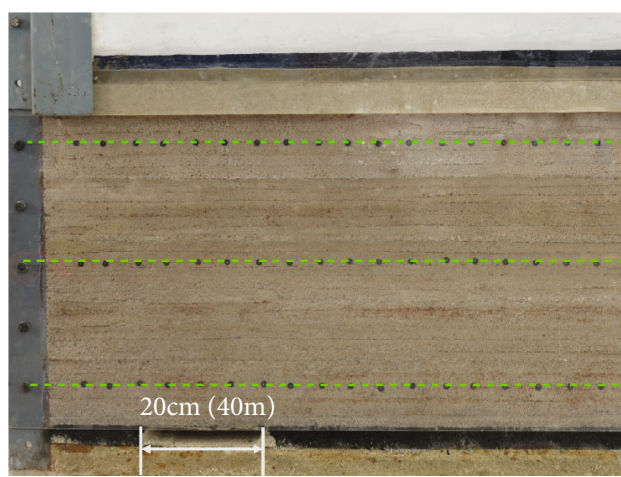

(a) Excavated to $40 \mathrm{~m}$

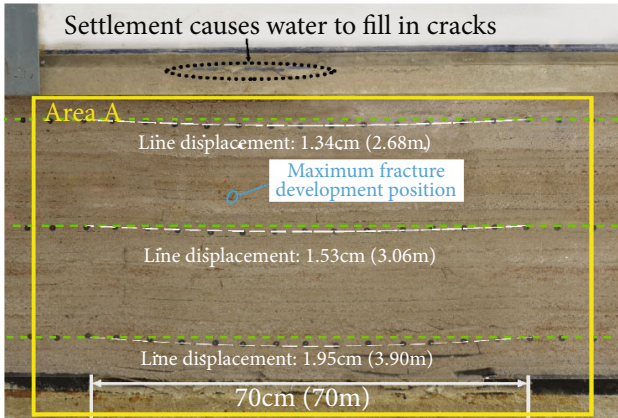

(c) Excavated to $140 \mathrm{~m}$

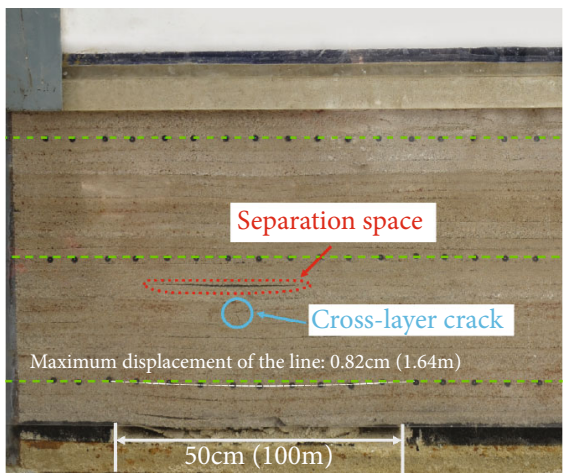

(b) Excavated to $100 \mathrm{~m}$

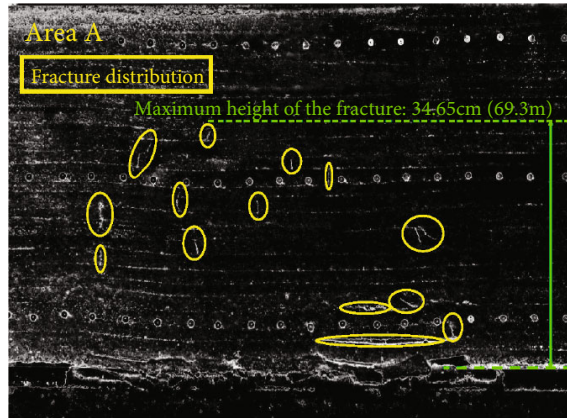

(d) Distribution of fracture development in Area A

FIgURE 7: The experimental results of mining period.

no new cracks are generated. Therefore, the height of the fracture zone tends to stabilise instead of continuously increase (Figure 9(d)).

4.1. Theoretical Model and Equations. To illustrate and verify the mechanism of water-conducting fracture development intuitively from a mechanical viewpoint, we simulate the excavation of the working face in the Yili coal mine by FLAC3D.
In FLAC3D, the Lagrange algorithm is used. From the Cauchy formula, the stress vector $t$ on any inclined plane can be obtained as

$$
\mathbf{t}_{i}=\boldsymbol{\sigma}_{i j} \mathbf{n}_{j},
$$

where $\boldsymbol{\sigma}_{i j}$ is the symmetric stress tensor of a known point in the medium, representing the stress state of the point and $\mathbf{n}$ is the unit normal vector on any inclined plane. 


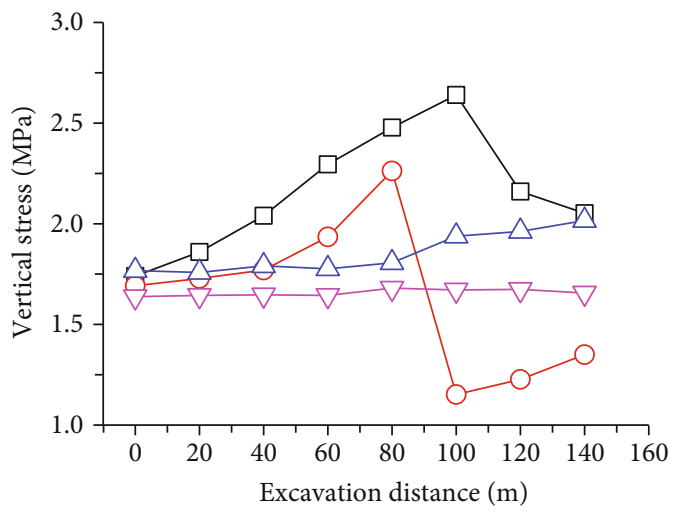

$\neg-$ No.1 stress sensor $\triangle$ No.3 stress sensor $-\bigcirc-$ No. 2 stress sensor $-\nabla-$ No.4 stress sensor

(a)

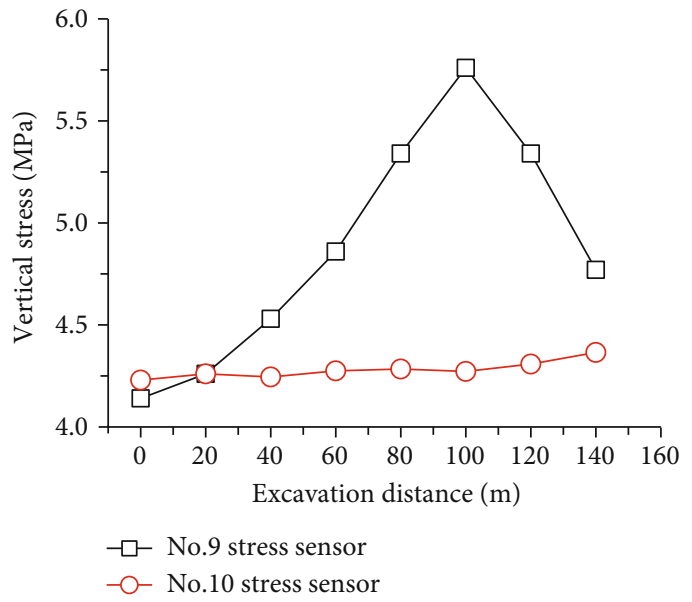

(c)

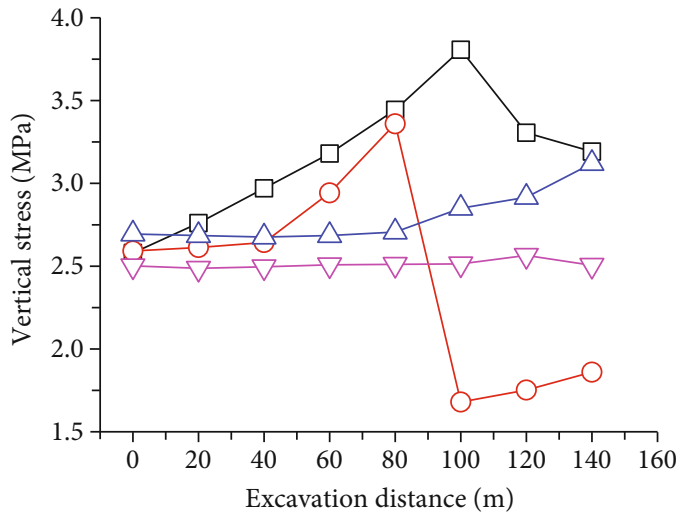

$\square$ No.5 stress sensor $\triangle-$ No.7 stress sensor

$-0-$ No.6 stress sensor $\quad-\nabla-$ No.8 stress sensor

(b)

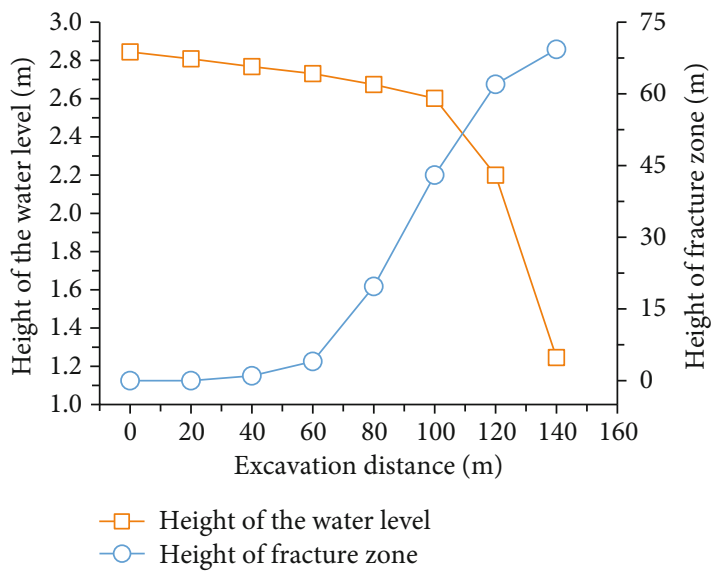

(d)

Figure 8: Vertical stress and height of the water level in the roof during the excavation process. (a) No. 1-No. 4, vertical stress. (b) No. 5-No. 8, vertical stress. (c) No. 9 and No. 10, vertical stress. (d) Height of water level and fracture zone.

If the particle has a velocity $v$, then in an infinitesimal time $\mathrm{dt}$, the medium will produce an infinitesimal strain determined by $v_{i} \mathrm{dt}$, and the corresponding strain rate component $\xi_{i j}$ is

$$
\xi_{i j}=\frac{1}{2}\left(\frac{\partial v_{i}}{\partial x_{j}}+\frac{\partial v_{j}}{\partial x_{i}}\right)
$$

Its rotation rate component $\omega_{i j}$ is

$$
\boldsymbol{\omega}_{i j}=\frac{1}{2}\left(\frac{\partial \boldsymbol{v}_{i}}{\partial \boldsymbol{x}_{j}}-\frac{\partial \boldsymbol{v}_{j}}{\partial \boldsymbol{x}_{i}}\right),
$$

where $x$ is the vector representing the position of the particle.

According to Newton's law of motion and Cauchy's principle of stress, if the particle acts on the stress $\boldsymbol{\sigma}_{i j}$ and the physical force $\mathbf{b}_{i}$ and has the velocity $v_{i}$, there is Cauchy's equation of motion in a very small time span $\mathrm{dt}$.

$$
\frac{\partial \boldsymbol{\sigma}_{i j}}{\partial \boldsymbol{x}_{j}}+\rho \mathbf{b}_{i}=\rho \frac{d \boldsymbol{v}_{i}}{\mathrm{dt}}
$$

where $\rho$ is the particle density.

If the acceleration of the particle is 0 , the above formula becomes the static equilibrium equation,

$$
\frac{\partial \boldsymbol{\sigma}_{i j}}{\partial \boldsymbol{x}_{j}}+\rho \mathbf{b}_{i}=0
$$

Equations (6) and (7) are the geometric equation and equilibrium differential equation, respectively, so the constitutive equation describing the relationship between the stress and strain of the medium is also needed. The definitions in FLAC3D are as follows:

$$
\widehat{\sigma}_{i j}=H_{i j}\left(\sigma_{i j}, \xi_{i j}, \kappa\right),
$$

where $\widehat{\sigma}_{i j}$ is the rate of stress change, $H$ is a known function, and $\kappa$ is a parameter related to the loading history. 


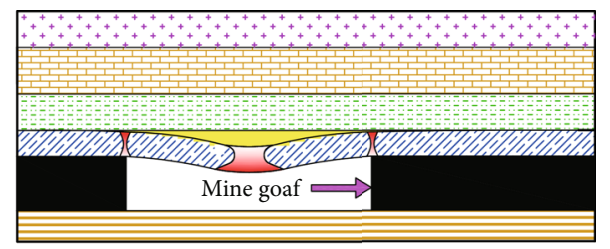

(a)

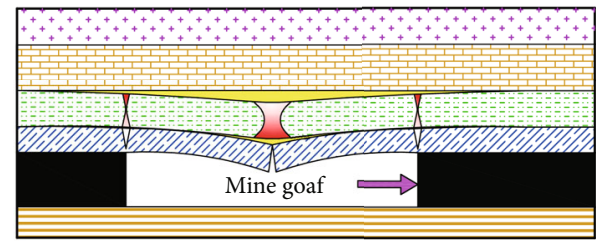

(b)

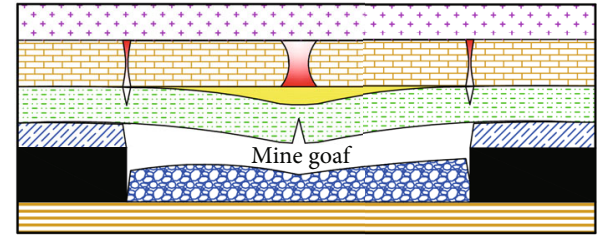

(c)

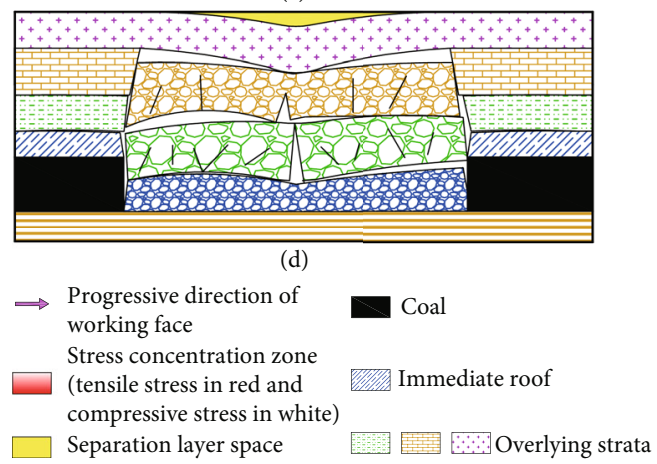

FIGURE 9: Generation and development mechanism of a waterconducting fracture zone. (a) Stress concentration occurs in the immediate roof when the working face advances. (b) Cracks appear in the immediate roof, and stress concentration occurs in the overlying strata. (c) The immediate roof collapse results in the development of cracks in the overlying strata. (d) Cracks cease to develop under the support of the collapse zone.

In FLAC3D, the constitutive model used in the elastic stage of the medium is a linear elastic model based on the generalised Hooke's law, including the isotropic elastic model, the orthotropic model, and the anisotropic model. In this paper, the isotropic elastic model is used in any single stratum, and its general expression is as follows:

$$
\left\{\begin{array}{c}
\varepsilon_{11} \\
\varepsilon_{22} \\
\varepsilon_{33} \\
\gamma_{12} \\
\gamma_{13} \\
\gamma_{23}
\end{array}\right\}=\left[\begin{array}{cccccc}
\frac{1}{E} & -\frac{\mu}{E} & -\frac{\mu}{E} & 0 & 0 & 0 \\
-\frac{\mu}{E} & \frac{1}{E} & -\frac{\mu}{E} & 0 & 0 & 0 \\
-\frac{\mu}{E} & -\frac{\mu}{E} & \frac{1}{E} & 0 & 0 & 0 \\
0 & 0 & 0 & \frac{1}{G} & 0 & 0 \\
0 & 0 & 0 & 0 & \frac{1}{G} & 0 \\
0 & 0 & 0 & 0 & 0 & \frac{1}{G}
\end{array}\right]\left\{\begin{array}{c}
\sigma_{11} \\
\sigma_{22} \\
\sigma_{33} \\
\tau_{12} \\
\tau_{13} \\
\tau_{23}
\end{array}\right\}
$$

where $E$ is the elastic modulus of the material, $\mu$ is Poisson's ratio, and $G$ is the shear modulus.

For the plastic stage, there are many constitutive models commonly used in geotechnical analysis, while for the excavation of rock and soil and the stability of the slope, the more commonly used model is the Mohr-Coulomb model [30]. Therefore, the Mohr-Coulomb model is selected as the plastic model of the numerical simulation in this paper. It mainly includes the shear failure criterion and tensile failure criterion; that is,

$$
\left\{\begin{array}{l}
f^{s}=\sigma_{1}-\sigma_{3} N_{\varphi}+2 c \sqrt{N_{\varphi}}=0, \\
f^{t}=\sigma_{3}-\sigma^{t}=0,
\end{array}\right.
$$

where $\sigma^{\mathrm{t}}$ is tensile strength, and $N_{\varphi}=1+\sin \varphi / 1-\sin \varphi$.

4.2. Model Establishment and Simulation Results. The model size and mechanical properties of each stratum are established according to the actual geological conditions (Figure 10). To eliminate the influence of the boundary effect, the height of the model is set to $200 \mathrm{~m}$, and the length is set to $600 \mathrm{~m}$. The left and right boundaries are limits in the $X$ displacement, the front and back boundaries are limits in the $Y$ displacement, and the bottom boundary is a limit in the $Z$ displacement. The upper boundary is a free boundary. Because of the weak strength of the silt layer and gravel layer in the upper part of the model, we regard these two layers as pressure boundaries. The strata above the third mudstone are not included in the research object, and their gravity is regarded as the external load. Thus, the pressure of the upper boundary can be calculated as $0.58 \mathrm{MPa}$. The location of the stress measurement points is consistent with those in the experiment.

Similar to the experimental results, the total excavation distance of the working face is $140 \mathrm{~m}$. Each excavation distance is $20 \mathrm{~m}$, and a total of 7 excavations are performed from left to right in turn. The distance from the open-off cut to the left boundary is $180 \mathrm{~m}$. The simulation results are shown in Figure 11.

According to the plastic zone and stress distribution map, the plastic zone (Figure 11(a)) develops in the coarse sandstone layer at the top of the main aquifuge, with a height of approximately $78 \mathrm{~m}$. The overburden structure experiences mainly tensile failure, which is reflected by the maximum principal stress (Figure 11(b)). The main reason for the failure of coarse sandstone layers is that the internal failure of tensile stress reaches the tensile strength limit of the layer, which is determined by the bending subsidence. The experimental results show that the generation and development of fractures on both sides and in the middle of the strata are consistent with the distribution of maximum principal stress (Figure 11(b)) and direction of shear stress (Figure 11(c)). With the excavation of the working face, the limit of the stress and plastic zone increases. The position of maximum vertical stress (Figure 11(d)) in overburden strata appears directly above the goaf. After the advancement of the working face, a pressure relief zone appears in the roof, and the 


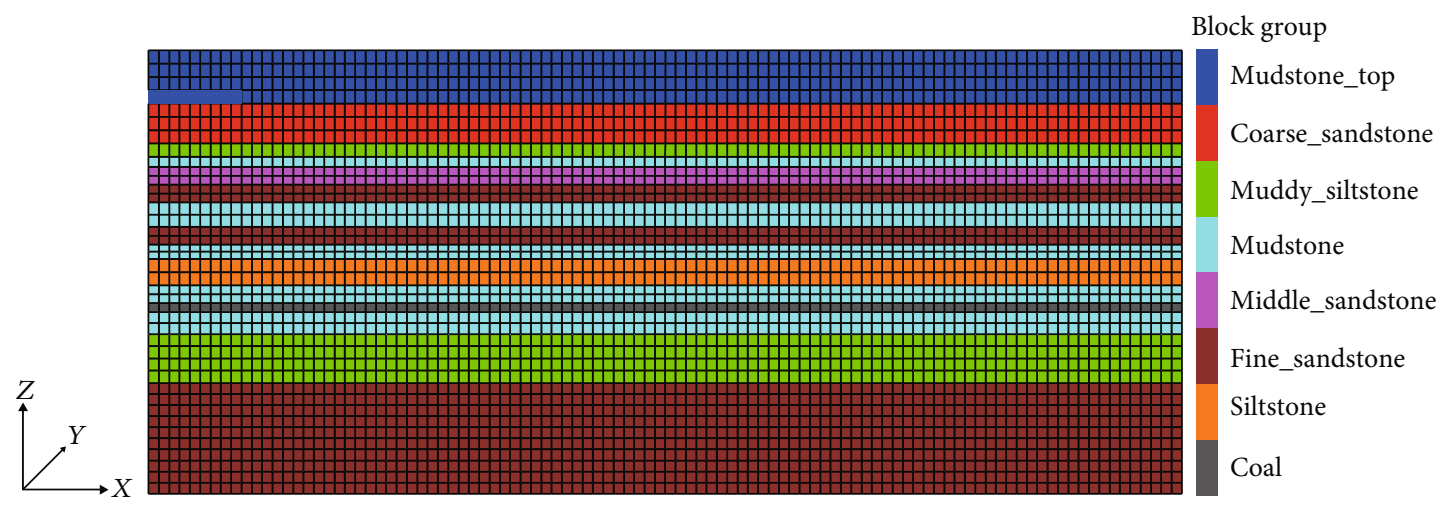

Figure 10: Numerical simulation model.

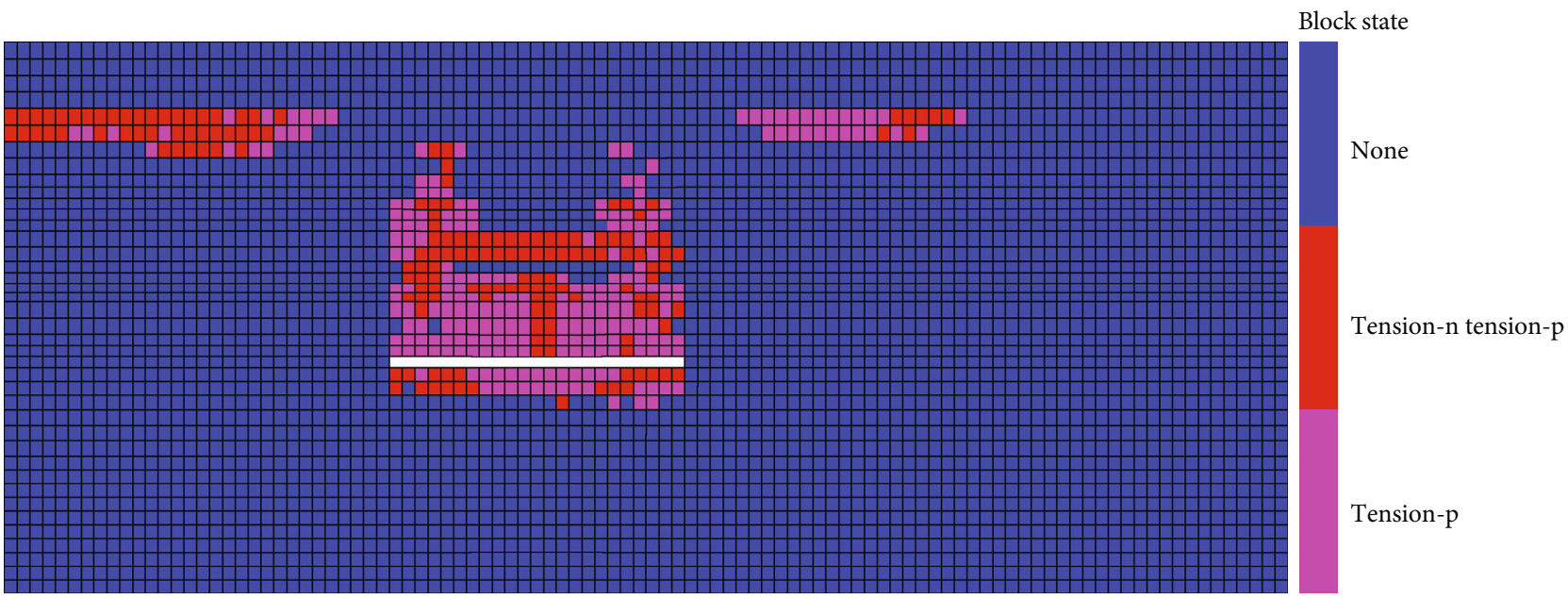

(a) Map of the plastic zone at $140 \mathrm{~m}$

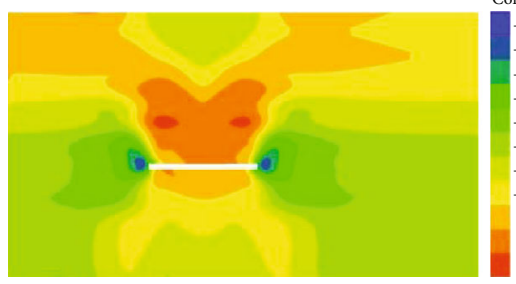

(b) Principle stress distribution map

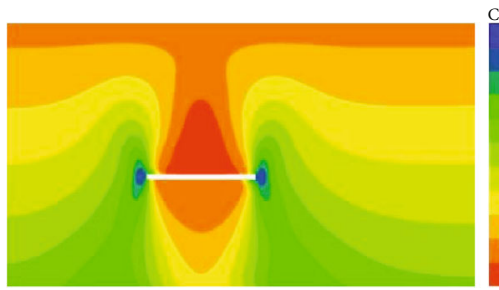
(d) Vertical stress distribution map

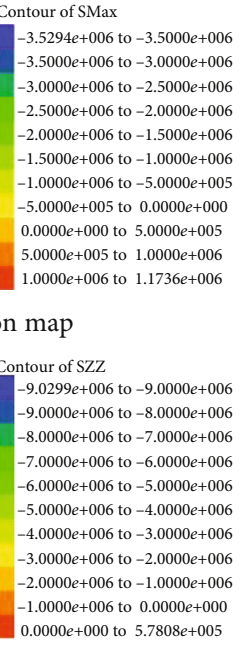

FIgure 11: Plastic zone and stress distribution map. stress in the overburden strata decreases gradually, which is close to the experimental results. However, the displacement values (Figure 11(e)) are smaller than those determined in the experiment. The main reason is that the finite difference method (FDM) cannot reflect the fracture and collapse of rock strata. When the excavation distance reaches $240 \mathrm{~m}$, the height of the plastic zone in the strata directly above the goaf has stabilised at approximately $80 \mathrm{~m}$. The plastic zones on both sides of the aquifer mudstone and aquifuge coarse sandstone have developed extensively due to bending and 


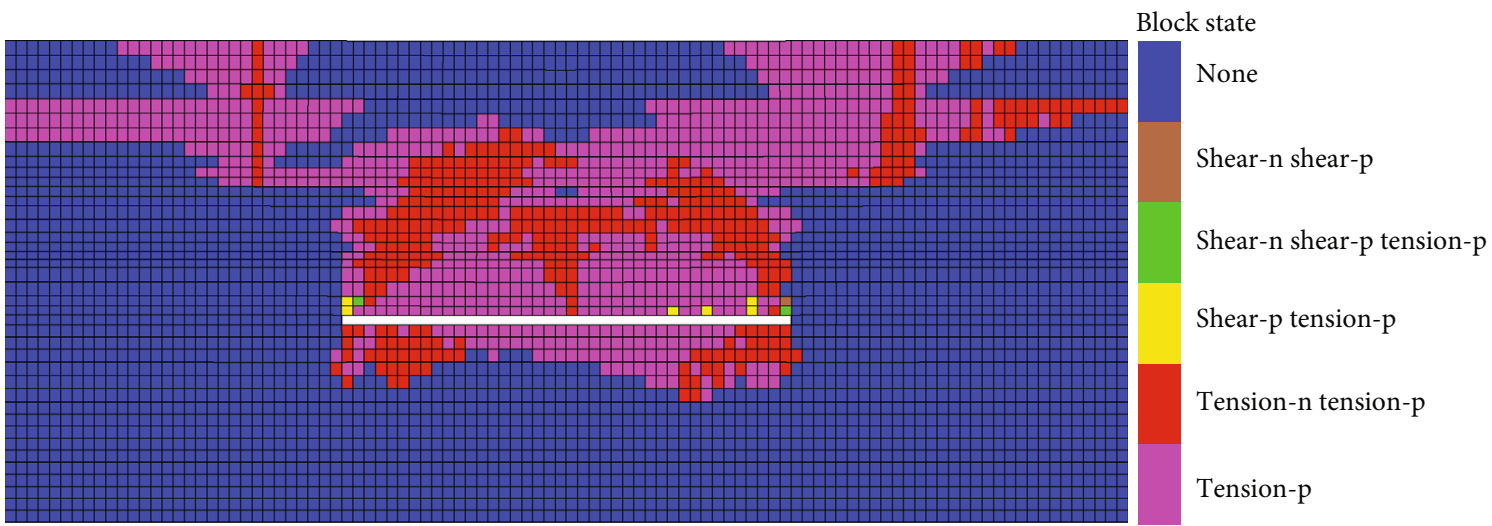

FIgURE 12: Distribution of plastic zone at excavation $240 \mathrm{~m}$.

subsidence. As a result, the plastic zone penetrates the aquifer (Figure 12). Overall, the simulation results are close to the experimental results, which verifies the correctness of the mechanistic analysis.

\section{Discussion}

5.1. Correlation between the Excavation Distance of the Working Face and the Development of the Fracture Zone. Controlling the maximum height of the water-conducting fracture zone is one of the main discriminant methods for water control in mining engineering. In engineering, to predict and prevent water inrush during mining, it is necessary to ensure that the maximum height of the waterconducting fracture zone does not exceed the height between the coal seam and the aquifer. At present, an empirical formula (Equation (12)) is usually used in engineering to predict the maximum height of the water-conducting fracture zone of weak overburden (compressive strength less than $20 \mathrm{MPa}$ ) in mining [31].

$$
H_{f}=\frac{100 M}{5.1 n+5.2}+5.1
$$

where $M$ is the thickness of the coal seam and $n$ is the number of coal seams.

For the working face in the Yili coal mine, Xinjiang, we apply the geological data obtained from field tests to empirical formulas. The thickness of the coal seam is $4 \mathrm{~m}$, and the number of coal seams is 1 . Therefore, the maximum height of the water-conducting fracture zone in long-wall mining is approximately $43.93 \mathrm{~m}$.

Because of the inhomogeneity of the distribution of overlying strata, we also test the empirical formula (Equation (13)) for the maximum height of the water-conducting fracture zone in coal mines with medium-strength overburden (compressive strength between $20 \mathrm{MPa}$ and $40 \mathrm{MPa}$ ).

$$
H_{f}=\frac{100 M}{3.3 n+3.8}+5.1
$$

The maximum height of the fractured zone is $61.43 \mathrm{~m}$.

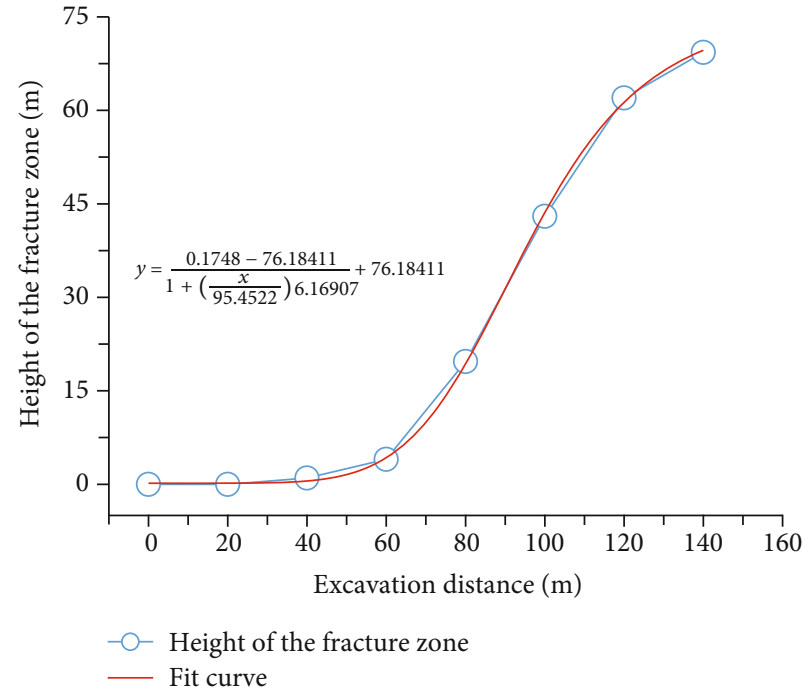

Figure 13: Curve fitting.

The experimental results reveal that the height of the fracture zone reaches $21.5 \mathrm{~cm}(43 \mathrm{~m})$ when the working face advances to $50 \mathrm{~cm}(100 \mathrm{~m})$. When the excavation distance reaches $70 \mathrm{~cm}(140 \mathrm{~m})$, the height of the fracture zone is $34.65 \mathrm{~cm}(69.3 \mathrm{~m})$, which is obviously higher than the height calculated by the empirical formula.

To quantitatively explore the relationship between the excavation distance and the height of the fracture zone, a nonlinear fitting is made between the excavation distance and the height of the fracture zone (Figure 13). The results show that the fit converges where the Chi-square tolerance is $1 e-9, R$-square (COD) is 0.99975 and Adj. $R$-square is 0.99956, indicating that the fitting result is satisfactory.

From the fitting results, we find that the height of the water-conducting fracture zone in the overburden structure tends to be stable during mining, which is also consistent with the engineering results for another overburden in a shallow seam mine [32]. On the basis of calculations with increasing excavation distance, it is found that the height of the fracture zone steadily increases, and the maximum height of the water fracture zone is approximately $76.18 \mathrm{~m}$. 
TABLE 3: Field drilling results of overburden fracture height in 21103 working face of 21-1 coal seam.

\begin{tabular}{lccccc}
\hline Working face & Coal & Drilling number & Mining thickness $(\mathrm{m})$ & Height of caving zone $(\mathrm{m})$ & Height of fissure zone $(\mathrm{m})$ \\
\hline \multirow{2}{*}{21103} & $21-1$ & $\mathrm{CH} 01$ & 3.8 & 12.55 & 80.47 \\
& & $\mathrm{Ch02}$ & & 10.98 & 72.76 \\
\hline
\end{tabular}

On the basis of the observations from the borehole test (Table 3) of failure in the overlying strata in the 21-1 coal seam at the 21103-working face [33], the height of the caving zone is approximately $10.98-12.55 \mathrm{~m}$, and the height of the fracture zone is $72.76-80.47 \mathrm{~m}$. The average height of the fracture zone can be calculated to approximately $76.615 \mathrm{~m}$. The field test results are very close to the experimental fitting results, but there is a large gap in the results of the empirical formula. While proving the validity of the experiment, the traditional empirical formula is not proven suitable for calculating the maximum height of the water-conducting fractured zone in the overburden in shallow seam mining.

5.2. Other Influencing Factors and Follow-Up Study. According to previous studies, the factors impacting water inrush include the stress in the primary rock, the original overburden structure, and the water pressure [11]. This paper focuses on the unique Yili coal mine, Xinjiang, where the strength of overlying strata is weak and there is no extremely water-rich confined aquifer. Surface water and shallow groundwater are the main sources of recharge. Therefore, the different conditions of in situ stress, lithology, and confined aquifers that may exist in other shallow mining areas are not considered, and the study of other factors impacting the development of a water-conducting fracture zone in shallow seam mining and the universal laws governing this development are the focus of future work.

\section{Conclusions}

Physical similarity models are used to simulate the evolution mechanism of a water-conducting fracture zone according to the coal seam-overlying aquifer arrangement in the Yili coal mine, Xinjiang. The water-conducting fracture zone gradually expands with increasing mining distance. Moreover, the spreading speed tends to gradually increase, showing an obvious nonlinear distribution. The critical water-conducting fracture zone is reached at an excavation depth of $60 \mathrm{~cm}(120 \mathrm{~m})$. Moreover, the depth of the fracture zone reaches $31 \mathrm{~cm}(62 \mathrm{~m})$ and begins to penetrate the main aquifer. When the mining proceeds to $70 \mathrm{~cm}(140 \mathrm{~m})$, the fracture completely penetrates the main aquifer of coarse sandstone, causing serious instability in the subsidence of the upper mudstone strata and a sharp decrease in the water level.

We also analyse the main mechanism of the evolution of the water-conducting fracture zone. After mining, the roof bends under the action of overlying strata and its own gravity. When the ultimate stress is exceeded, the fracture develops. We use FlAC3D to simulate coal seam excavation. The simulation results verify the correctness of the stress distribution in the testing and analysis. As mining continues, the fracture zone tends to stabilise and no longer grow primarily because the overlying strata are gradually supported by the collapsed strata. As a result, the overlying strata are no longer deformed, and the internal stress strength gradually fails to reach the ultimate stress strength.

By fitting the relationship between the depth of the fracture zone and the excavation distance, we find that the experimental results are similar to the field drilling test results. This proves the correctness and feasibility of the experimental methodology and demonstrates that the traditional empirical formula requires modification for calculation of the maximum depth of the water-conducting fracture zone in shallow seams in Northwest China.

\section{Data Availability}

In our manuscript, the experiment and test data used to support the findings of this study are available from the corresponding author upon request.

\section{Conflicts of Interest}

No conflict of interest exists in the submission of this manuscript.

\section{Acknowledgments}

This study was supported by the Special Subject Grant of National "973" Basic Research Program of China (No. 2015CB251602), National Science and Technology Major (2016ZX05043), Jiangsu Natural Science Foundation (BK20180636), Independent Innovation Project for Double First-level Construction of CUMT (2018ZZCX04), Advance Research Program of (LTKY201803), and China and Jiangsu Postdoctoral Science Foundation (2019M65201).

\section{Supplementary Materials}

There are two tables in the supplementary materials. Table S-1 is the orthogonal experiment scheme of the sample proportions of similar materials. Table S-2 is results of orthogonal experiment. Two tables have been marked in the form of Table S-1 and Table S-2 in the manuscript. (Supplementary Materials)

\section{References}

[1] D. Xu, S. Peng, S. Xiang, M. Liang, and W. Liu, "The effects of caving of a coal mine's immediate roof on floor strata failure and water inrush," Mine Water and the Environment, vol. 35, no. 3, pp. 337-349, 2016.

[2] W. Li, Y. Liu, W. Qiao, C. Zhao, D. Yang, and Q. Guo, “An improved vulnerability assessment model for floor water 
bursting from a confined aquifer based on the water inrush coefficient method," Mine Water and the Environment, vol. 37, no. 1, pp. 196-204, 2018.

[3] J. Pope and D. Craw, "Current research on mine water and the environment in New Zealand," Mine Water and the Environment, vol. 34, no. 4, p. 363, 2015.

[4] L. Zhu, D. Fan, R. Ma, Y. Zhang, and Y. Zha, "Experimental and numerical investigations of influence on overland flow and water infiltration by fracture networks in soil," Geofluids, vol. 2018, Article ID 7056858, 16 pages, 2018.

[5] H. Yin, H. Zhao, D. Xie, S. Sang, Y. Shi, and M. Tian, "Mechanism of mine water inrush from overlying porous aquifer in quaternary: a case study in Xinhe Coal Mine of Shandong Province, China," Arabian Journal of Geosciences, vol. 12, no. 5, p. 163, 2019.

[6] Y. Hu, J. Sun, W. Liu, and D. Wei, "The evolution and prevention of water inrush due to fault activation at working face no. II 632 in the Hengyuan coal mine," Mine Water and the Environment, vol. 38, no. 1, pp. 93-103, 2019.

[7] P. Bukowski, "Water hazard assessment in active shafts in Upper Silesian Coal Basin mines," Mine Water and the Environment, vol. 30, no. 4, pp. 302-311, 2011.

[8] V. N. Odintsev and N. A. Miletenko, "Water inrush in mines as a consequence of spontaneous hydrofracture," Journal of Mining Science, vol. 51, no. 3, pp. 423-434, 2015.

[9] A. Pourjabbar, C. Sârbu, K. Kostarelos, J. W. Einax, and G. Büchel, "Fuzzy hierarchical cross-clustering of data from abandoned mine site contaminated with heavy metals," Computers \& Geosciences, vol. 72, pp. 122-133, 2014.

[10] R. Jiang, H. Zhou, H. Wang, and S. S. Ge, "Maximum entropy searching," CAAI Transactions on Intelligence Technology, vol. 4, no. 1, pp. 1-8, 2019.

[11] J. Zhang, "Investigations of water inrushes from aquifers under coal seams," International Journal of Rock Mechanics and Mining Sciences, vol. 42, no. 3, pp. 350-360, 2005.

[12] B. Yao, H. Bai, and B. Zhang, "Numerical simulation on the risk of roof water inrush in Wuyang coal mine," International Journal of Mining Science and Technology, vol. 22, no. 2, pp. 273-277, 2012.

[13] Q.-S. Bai and S.-H. Tu, "Failure analysis of a large span longwall drift under water-rich roofs and its control techniques," Engineering Failure Analysis, vol. 67, pp. 15-32, 2016.

[14] A. Majdi, F. P. Hassani, and M. Y. Nasiri, "Prediction of the height of destressed zone above the mined panel roof in longwall coal mining," International Journal of Coal Geology, vol. 98, pp. 62-72, 2012.

[15] M. Nasihatgozar, "Analysis of buckling in concrete beams containing nanoparticles utilizing numerical approach," International Journal of Hydromechatronics, vol. 2, no. 1, p. 1, 2019.

[16] M. Cinefra, "Numerical method for frequency response in visco-embedded nanoplate," International Journal of Hydromechatronics, vol. 2, no. 1, p. 1, 2019.

[17] D. Kong, W. Jiang, Y. Chen, Z. Song, and Z. Ma, "Study of roof stability of the end of working face in upward longwall top coal," Arabian Journal of Geosciences, vol. 10, no. 8, p. 185, 2017.

[18] C. Wang, C. Zhang, X. Zhao, L. Liao, and S. Zhang, "Dynamic structural evolution of overlying strata during shallow coal seam longwall mining," International Journal of Rock Mechanics and Mining Sciences, vol. 103, pp. 20-32, 2018.
[19] X. Wang, X. Liu, E. Wang et al., "Experimental research of the AE responses and fracture evolution characteristics for sandparaffin similar material," Construction and Building Materials, vol. 132, pp. 446-456, 2017.

[20] S. Zhang, W. Guo, Y. Li, W. Sun, and D. Yin, "Experimental simulation of fault water inrush channel evolution in a coal mine floor," Mine Water and the Environment, vol. 36, no. 3, pp. 443-451, 2017.

[21] K. W. Mills, O. Garratt, B. G. Blacka, L. C. Daigle, A. C. Rippon, and R. J. Walker, "Measurement of shear movements in the overburden strata ahead of longwall mining," International Journal of Mining Science and Technology, vol. 26, no. 1, pp. 97-102, 2016.

[22] S. Krisnanto, H. Rahardjo, D. G. Fredlund, and E. C. Leong, "Water content of soil matrix during lateral water flow through cracked soil," Engineering Geology, vol. 210, pp. 168-179, 2016.

[23] S. Chen, H. Wang, J. Zhang, H. Xing, and H. Wang, "Lowstrength similar materials for backfill mining: insight from experiments on components and influence mechanism," Geotechnical Testing Journal, vol. 38, no. 6, article 20140103, 2015.

[24] B. Guo, T. Cheng, L. Wang, T. Luo, and X. Yang, "Physical simulation of water inrush through the mine floor from a confined aquifer," Mine Water and the Environment, vol. 37, no. 3, pp. 577-585, 2018.

[25] D. Z. Gu, “Technology development and engineering practice for protection and utilization of water resources in coal mining in Western China," Frontiers of Engineering Management, vol. 3, no. 1, p. 59, 2016.

[26] Q. Zhang, S. Li, X. Guo, Y. Li, and H. P. Wang, "Research and development of new typed cementitious geotechnical similar material for iron crystal sand and its application," Rock and Soil Mechanics, vol. 29, no. 8, pp. 2126-2130, 2008.

[27] S. Li, X. Feng, S. Li, L. Li, and G. Li, "Research and development of a new similar material for solid-fluid coupling and its application," Chinese Journal of Rock Mechanics and Engineering, vol. 29, no. 2, pp. 281-288, 2010.

[28] K. Wang, S. C. Li, Q. S. Zhang et al., "Development and application of new similar materials of surrounding rock for a fluidsolid coupling model test," Rock and Soil Mechanics, vol. 37, no. 9, pp. 2521-2533, 2016.

[29] H. Wang, J. Xi, Y. Gao, and Q. Hou, "Similarity criterion analysis of goaf similar material simulation," in Proceedings of 2012 (Shenyang) International Colloquium on Safety Science and Technology, pp. 11-14, Shenyang, China, 2012.

[30] S. Sun, H. Lin, and L. Ren, Application of FLAC3D in Geotechnical Engineering, China Water \& Power Press, Beijing, China, 2011.

[31] SACMSC (State Administration of Coal Mine Safety of China), Interpretation of the Regulations of Mine Water Disaster Prevention, China Univ of Mining and Technology Press, Xuzhou, China, 2009.

[32] X. Huo, Study on Overlying Rock Failure Above Large Mining Height Longwall Face with Shallow Cover and Development Height of Water Flowing Fractured Zone, Xi'an University of Science and Technology, Xi'an, China, 2018.

[33] P. Xiong, W. Hu, and M. Zhu, "Study and analysis of overburden failure height in Yibei mining area of Xinjiang," China Science \& Technology Overview, vol. 15, p. 122, 2017. 